Classification

Physics Abstracts

81.30. $\mathrm{Hd}-81.30 . \mathrm{Bx}-72.80 . \mathrm{Ng}$

\title{
Local Order and Associated Deformation Mechanisms in the $\gamma$ Phase of Nickel Base Superalloys
}

\author{
Nicole Clément $\left({ }^{1}\right)$, Armand Coujou $\left({ }^{1}\right)$, Yvonne Calvayrac $\left({ }^{2}\right)$, François Guillet $\left({ }^{2}\right)$, \\ Didier Blavette $\left({ }^{3}\right)$ and Stéphane Duval $\left({ }^{3}\right)$ \\ ( $\left.{ }^{1}\right)$ CEMES-LOE/CNRS, 29 rue Jeanne Marvig, BP. 4347, 31055 Toulouse Cedex, France \\ $\left({ }^{2}\right)$ CECM/CNRS, 15 rue Georges Urbain, 94407 Vitry Cedex, France \\ $\left({ }^{3}\right)$ LMI, URA CNRS 808, UFR Sciences et Techniques, BP. 118, 76134 Mont Saint Aignan Cedex, \\ France
}

(Received November 6, 1995; accepted January 30, 1996)

\begin{abstract}
Using X-ray diffraction, atom probe nanoanalysis, T.E.M. associated with in situ deformation, the presence of local order in the $\gamma$ matrix of a monocrystalline MC2 superalloy is demonstrated. In $\mathrm{Ni}_{2} \mathrm{CoCr}$ the model alloy of this phase, as well as in the $\gamma \mathrm{MC} 2$ matrix, the existence at room temperature of a strong short range order of $\left\{\begin{array}{lll}1 & 1 / 2 & 0\end{array}\right\}$ special point type is emphasized. It induces high friction stresses opposing the movement of dislocations which have to propagate in planar arrays in the corresponding materials. In addition, long range ordered $\mathrm{L}_{2}$ hyperfine precipitates appear in the $\gamma \mathrm{MC1}$ samples annealed at $750^{\circ} \mathrm{C}$. They induce several pairs of dislocations at the head of the moving pile-ups in order to cut them.
\end{abstract}

\section{Introduction}

Due to their significant improvements in creep and fatigue strength over conventional materials, monocrystalline nickel base superalloys have been extensively studied. Much information concerns the characteristics of the two-phase alloy and the $\gamma^{\prime}$ phase (mechanical tests, intrinsic stacking fault energies, antiphase boundary energies, etc.). On the other hand very little information is available on the $\gamma$ matrix of these alloys even though such information is essential for the understanding of the $\gamma$ phase contribution to the mechanical properties of the superalloy.

The aim of this work is to study the local order in the $\gamma$ phase, combining different techniques on the same samples: X-ray diffraction, which provides a global description of the short range ordering state, reflected in the diffraction pattern by diffuse scattering; atom probe nanoanalysis which makes it possible to study the material microchemistry on a near-atomic scale; T.E.M. associated with in situ deformation which allow the direct observation of the real space on a nanoscopic and a microscopic scale. The influence of local order on the microscopic mechanisms which control the deformation is emphasized. 


\section{Experimental}

2.1 Preparation of Samples. - Two kinds of samples are considered here: single crystals having the composition of the $\gamma$ matrix of the $\mathrm{MC} 2$ superalloy, and $\mathrm{Ni}_{2} \mathrm{CoCr}$ samples. This latter alloy, made of the three major components of the industrial $\gamma$ phase, may be considered as a "model" of the $\gamma$ phase. Ni and Cr levels are close to those of $\gamma$; the Co concentration was chosen in order to optimize the conditions of the X-ray diffuse scattering study. Both single crystals and polycrystalline samples were prepared.

- The $\gamma$ phase single crystals, axis [100], were specially elaborated at the ONERA with a composition equal to that of the $\gamma$ matrix of the $\mathrm{MC} 2$ at $T=850^{\circ} \mathrm{C}[1,2]$. The measured composition, very similar to the matrix one, is given in Table I. The large amounts of chromium and cobalt existing in this phase allow a comparison with binary $\mathrm{Ni}-\mathrm{Cr}$ and ternary Ni-Cr-Co alloys. These specimen.were homogenized $3 \mathrm{~h}$ at $1300^{\circ} \mathrm{C}$ and air cooled.

Table I. - Atom probe data from Duval et al. [2]: composition (atomic \%) of each individual phase of the $\gamma / \gamma^{\prime} M C 2$ superalloy and of the $\gamma$ one-phase material for $T=850{ }^{\circ} \mathrm{C}$.

\begin{tabular}{|c|c|c|c|c|c|c|c|c|}
\hline & $\mathrm{Ni}$ & $\mathrm{Cr}$ & $\mathrm{Co}$ & $\mathrm{Al}$ & $\mathrm{Ta}$ & $\mathrm{W}$ & $\mathrm{Ti}$ & $\mathrm{Mo}$ \\
\hline $\mathrm{MC} 2 \gamma^{\prime}$ & 70.9 & 1.8 & 3.5 & 14.8 & 2.2 & 3.1 & 3.1 & 0.6 \\
\hline $\mathrm{MC} 2 \gamma$ & 55.4 & 25.9 & 9.1 & 2.9 & 0.3 & 4.1 & 0.3 & 2.75 \\
\hline MC2 $\gamma$ single phase & 54.62 & 26.04 & 9.15 & 2.74 & 0.28 & 4.16 & 0.24 & 2.78 \\
\hline
\end{tabular}

- The polycrystalline $\mathrm{Ni}_{2} \mathrm{CoCr}$ alloy was prepared from $99.95 \%$ pure metals by melting in a high frequency vacuum furnace, followed by casting into a water-cooled copper mould. A piece of this ingot was cold-rolled in order to obtain samples for the in situ study of the deformation by electron microscopy. A single crystal was grown from the same ingot for both the X-ray diffuse scattering study and the atom probe microanalysis. This crystal was grown by the Bridgman technique. A disk-shape sample ( $2 \mathrm{~mm}$ in height, $18 \mathrm{~mm}$ in diameter and with a [112] axis) was cut by spark erosion for the X-ray study. For the atom probe study $\langle 001\rangle$ oriented square rods were cut from an immediately adjacent portion of the crystal. The actual composition as determined by EDX is Ni-51.2 Co-26.05 Cr-22.75at\%. The composition was found to be homogeneous over the total crystal section within 0.1 at. $\%$.

All the investigations (with the three techniques used) were made on samples annealed for 24 hours at $500{ }^{\circ} \mathrm{C}$ and water-quenched. A systematic study of the resistivity after annealing ensured that the equilibrium state of short range order (SRO) is attained after this annealing time.

2.2 Observations of Deformed Samples. - Three types of observations at different scales are described in the following. They allow the comparison of the microstructures created in the bulk and in the thin foil, in a dynamic and static way, under load and relaxed.

- Observations by S.E.M of slip lines at the surface of macroscopically deformed samples (deformation $\varepsilon \cong 2 \%$ ).

- "Post-mortem" observations by T.E.M. on the same samples: Cuts parallel to $\{111\}$ were chosen and allow large arrays to be imaged in the corresponding glide planes.

- In situ deformation tests - They were performed at room temperature in a JEOL $200 \mathrm{CX}$ T.E.M., at $200 \mathrm{kV}$, using the procedure described earlier [3]. Similar to macroscopic experiments the tensile axis of the microsamples was $\langle 001\rangle$ (Schmit factor $\cong 0.43$ ). 

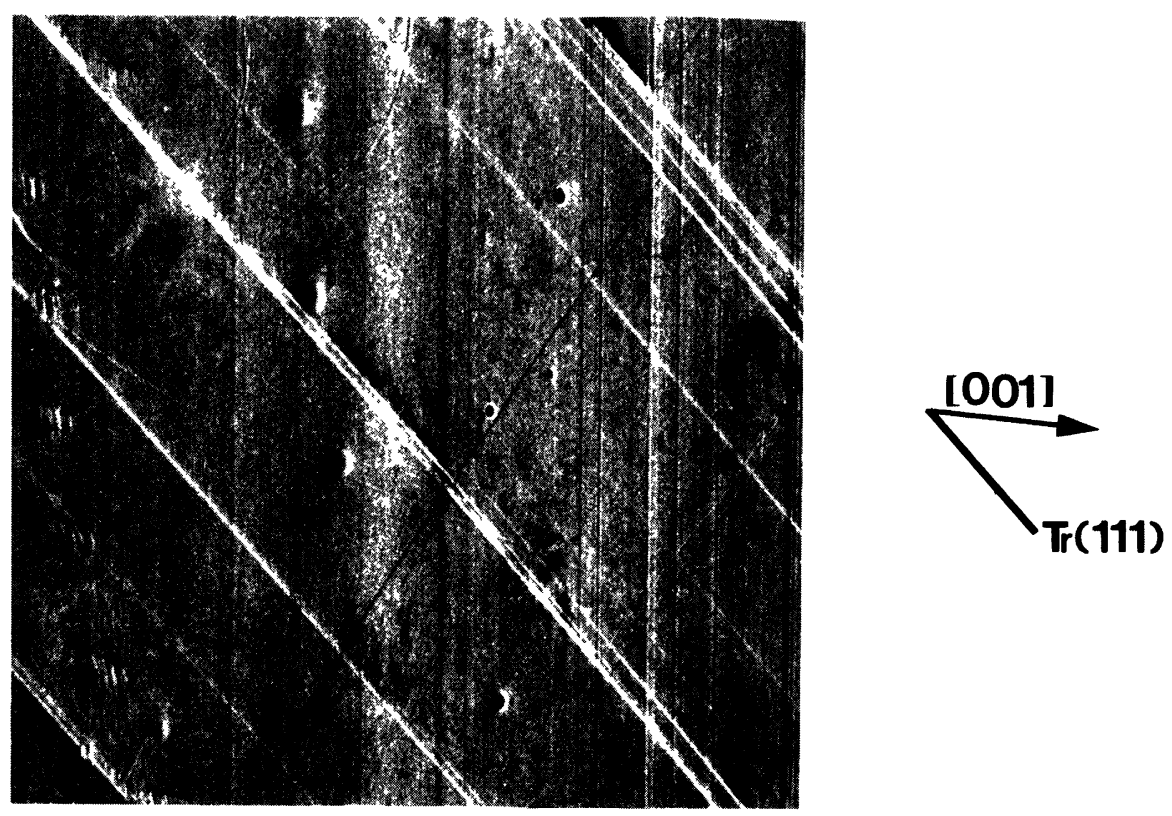

Fig. 1. - MC2 $\gamma$ phase. S.E.M. room temperature. Heterogeneous distribution of slip bands at the surface of a macroscopically deformed sample.

\section{Microstructure of Deformed Samples}

$3.1 \gamma \mathrm{MC} 2 .-$ Between $-196{ }^{\circ} \mathrm{C}$ and $900{ }^{\circ} \mathrm{C}$, whatever the observation scale, the most striking feature concerning the observed microstructure is the strong localization of the deformation, while above $900{ }^{\circ} \mathrm{C}$ it becomes homogeneous.

At a mesoscopic scale (Cambridge S.E.M, $20 \mathrm{kV}$ ) Figure 1 shows, at $25^{\circ} \mathrm{C}$ and for a low deformation $\varepsilon \cong 2 \%$, that slip bands corresponding to bundles of $\{111\}$ slip lines are created at the sample surface. Their frequency is very heterogeneous: slip zones 2.5 to $10 \mu \mathrm{m}$ large separated by 50 to $100 \mu \mathrm{m}$ wide zones, free of any traces, are observed.

Extracting thin foils from the same samples, parallel to the active slip bands, the T.E.M. observed microstructure shows the same heterogeneity. It consists of planar arrays of several dislocations activated in $\{111\}$ planes and heterogeneously distributed in the sample. This is very different from a classical F.C.C. disordered phase microstructure where individual dislocation movements create an homogeneously distributed deformation.

Figure 2a gives an example of such a static and relaxed configuration: here, thirty dislocations near edge orientation, gliding on the same plane from a source situated in A, having the same Burgers vector $(1 / 2[1 \overline{1} 0])$, is stopped without any apparent obstacle. In $X$, on the contrary an obstacle impedes the movement of glissile dislocations. Different from a classical pile-up, inside the first group, spacing between dislocations does not follow the expected scheme: instead of a regular increase of the spacing from the front to the back of the pile-up, pairs exist at the head of the pile-up. Measuring the distance between to successive dislocations, they can be evidenced when a minimum appears on the curve (three pairs in this case, Fig. 2b). 


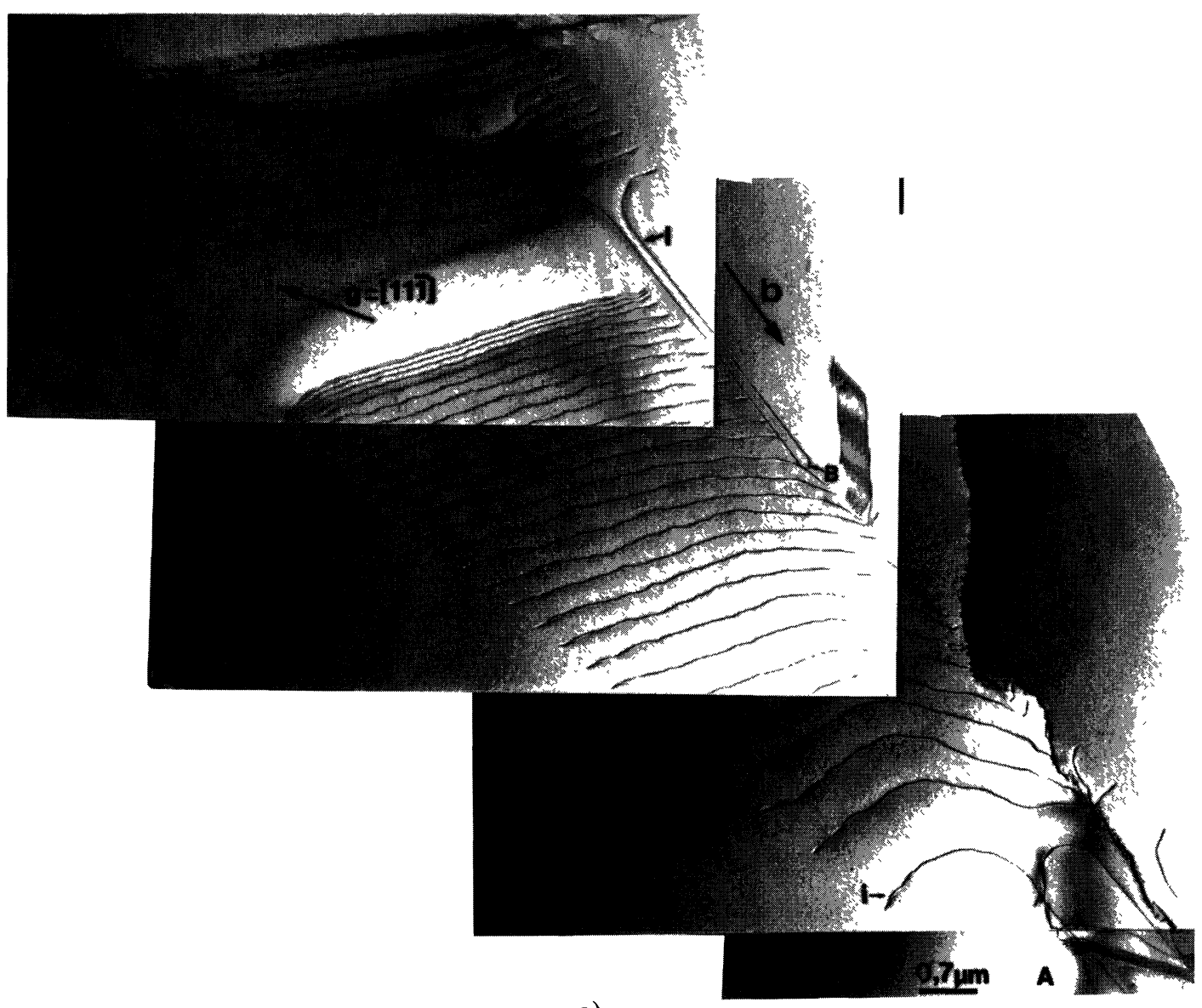

a)

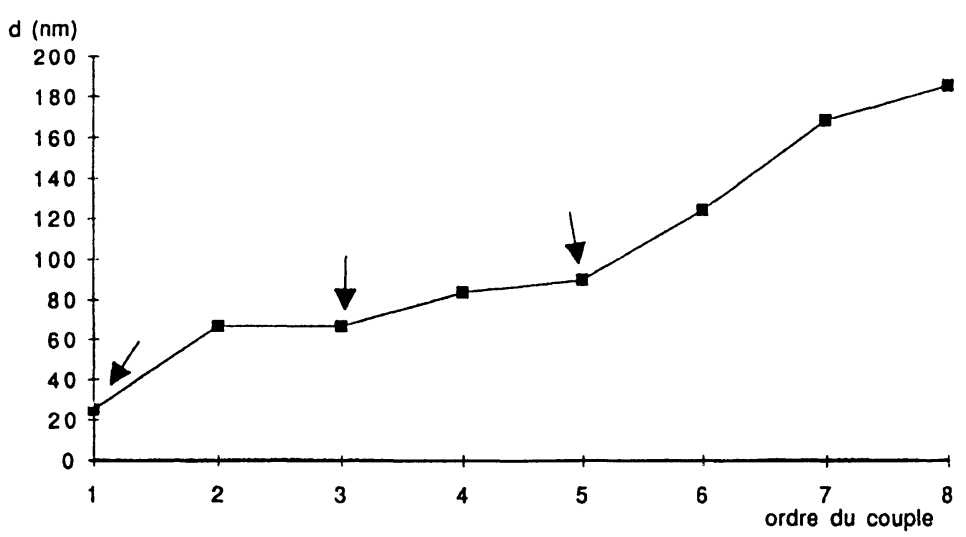

b)

Fig. 2. - MC2 $\gamma$ phase. a) Post mortem observation of a macroscopically deformed sample. A pile-up of thirty dislocations with a near edge orientation has been emitted from the source A during the deformation of the bulk. Three pairs of dislocations are observed at the front of the pile-up. B is an edge dipole, and X a hard region where an other pile-up is built. b) Measuring the space between two successive dislocations within the group three minima corresponding to three pairs are observed. 
When the $\gamma \mathrm{MC} 2$ samples are deformed at increasing temperatures, the number of pairs increases: from $2-3$ pairs at $25^{\circ} \mathrm{C}, 3-4$ pairs at $350{ }^{\circ} \mathrm{C}, 5-6$ pairs at $600{ }^{\circ} \mathrm{C}$ [29].

Furthermore during in situ experiments no individual dislocation was seen moving, the observed movements always concern groups of several tenths of dislocations. In some sequences, the movement of the pile-up head was recorded. Such a sequence is presented in Figure 3; the observed pile-up consists of a hundred dislocations (orientation $\alpha=12^{\circ}$ ) propagating in a $(-111)$ plane at the rate of 30 to $120 \mathrm{~nm} / \mathrm{s}$, depending on the imposed deformation rate. When the dislocations move, the observed movement is not jerky, it is calm and homogeneous. Several pairs of dislocations are visible, within a pair the movement of the two dislocations remained correlated and this correlation is visible until the sixth or seventh pair. When the deformation is stopped, dislocations are rarely observed to go in the reverse sense indicating that very high friction stresses are involved opposing their movement [8].

3.2 NiCr. - At room temperature, on binary Ni Cr alloys (20\% to 37 weight $\%$ of $\mathrm{Cr}$ ) similar results have been previously obtained [4]. But the number of pairs involved in the movement was lower than in the case of $\gamma \mathrm{MC} 2$ alloys. Also, in these alloys the dynamics observed during in situ experiments was different. The pile-up head velocity was very high, larger than $40 \mu \mathrm{m} / \mathrm{s}$ and uneven velocities were observed: bursts of dislocations propagate the deformation within the moving group.

3.3 $\mathrm{Ni}_{2} \mathrm{CoCr}$. - Figure 4 shows two examples of the observed configurations. As usually observed, in Figure 4a a pile-up created during the in situ deformation, is stopped without any apparent obstacle, one pair of dislocations is clearly visible at the head. Figure $4 \mathrm{~b}$ gives an example of a pile up, stopped near a grain boundary. In this case three pairs exist at the head of the planar moving group.

\section{On the Origin of the Planar Glide Observed in the $\gamma$ Phase}

The planar glide analyzed before is frequently observed in highly concentrated solid solutions (Cu-Al; $\mathrm{Cu}-\mathrm{Zn}$; [6]; Ni-Cr; [4]). Three different origins can be postulated [13, 7]:

- a large decrease of the stacking fault energy;

- the existence of a pronounced local order or short range clustering;

- or long range ordered finely dispersed particles.

Furthermore it has been demonstrated that the existence of local order is always associated with planar slip while non-planar arrangements can occur in alloys with a low stacking fault energy $[13,7]$.

4.1 Stacking Fault Energy. - Using different methods the stacking fault energy (S.F.E.) at room temperature, of the $\gamma$ phase was determined [8]. A mean value $\gamma_{\mathrm{i}} \cong 21 \mathrm{~mJ} / \mathrm{m}^{2}$ was obtained in the frame of elastic isotropy. It is of the same order as that measured in other superalloys (CMSX2', AM1, AM3) using the same techniques [9]. As summed up in Table II, an increase of the solute content in pure nickel induces a reduction of the corresponding S.F.E. [8]:

- by addition of chromium, it appears that the S.F.E. decreases from $140 \mathrm{~mJ} / \mathrm{m}^{2}$ (pure nickel), to $85 \mathrm{~mJ} / \mathrm{m}^{2}$ for $10 \%$ chromium, then it remains constant and rather high, around $75 \mathrm{~mJ} / \mathrm{m}^{2}$ between $15 \%$ and $38 \%$ of chromium [12],

- on the contrary, the addition of cobalt with a content quite similar to the $\gamma$ phase [11] induces a rapid decrease to $28 \mathrm{~mJ} / \mathrm{m}^{2}$ for a $\mathrm{Ni}-26 \% \mathrm{Cr}-10 \% \mathrm{Co}$. 

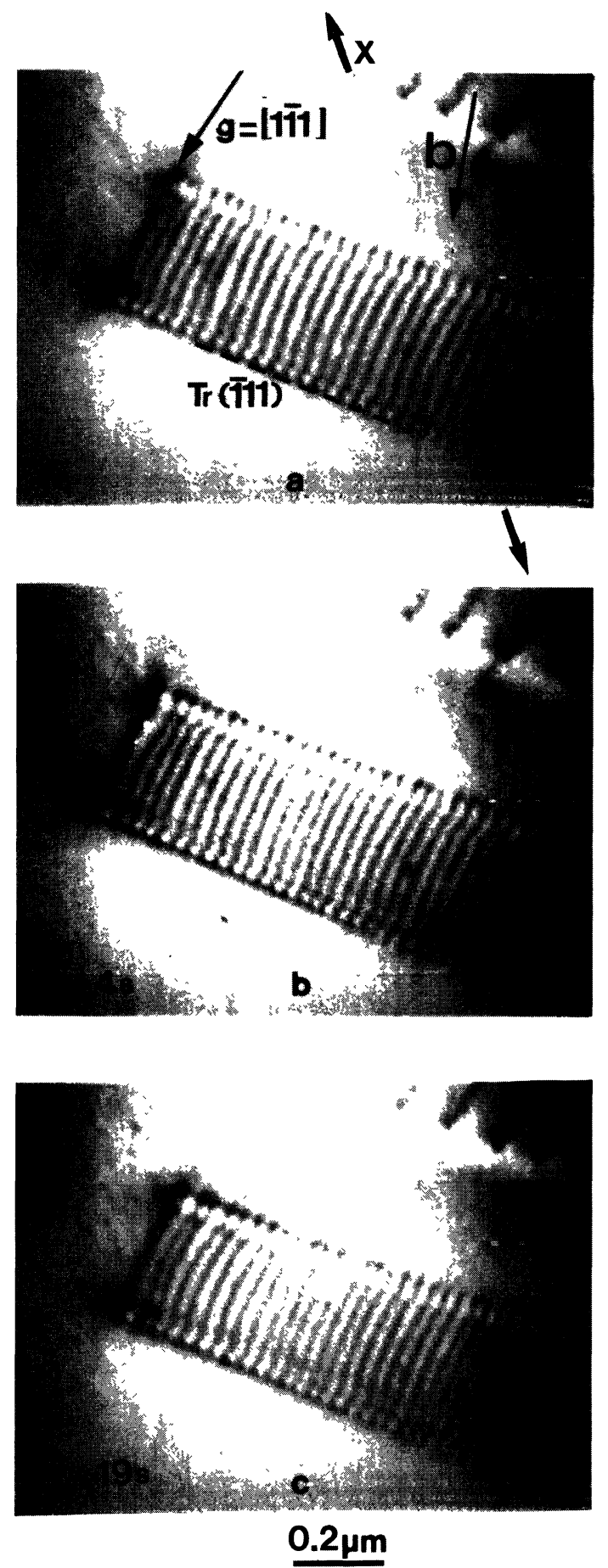

Fig. 3. - MC2 $\gamma$ phase. Dynamic sequence, in situ deformation. A near screw planar group of about one hundred dislocations is observed while moving. The movement of the five to seven first pairs of dislocations is correlated within each pair. The mean velocity is around $30 \mu \mathrm{m} / \mathrm{s}$. Y indicates a small defect which allows to measure the covered distance. 


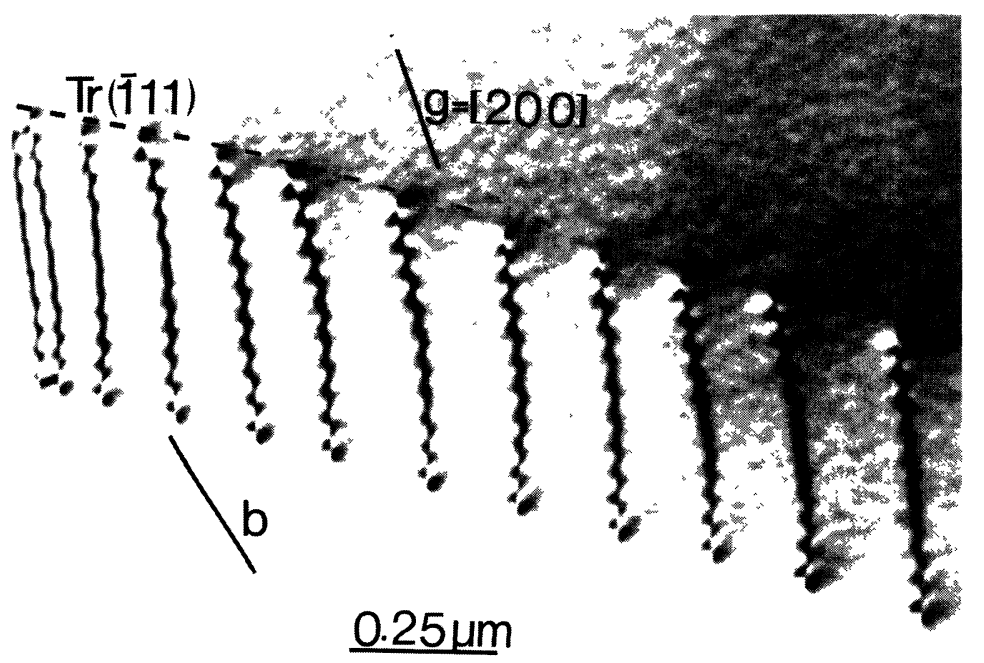

a)

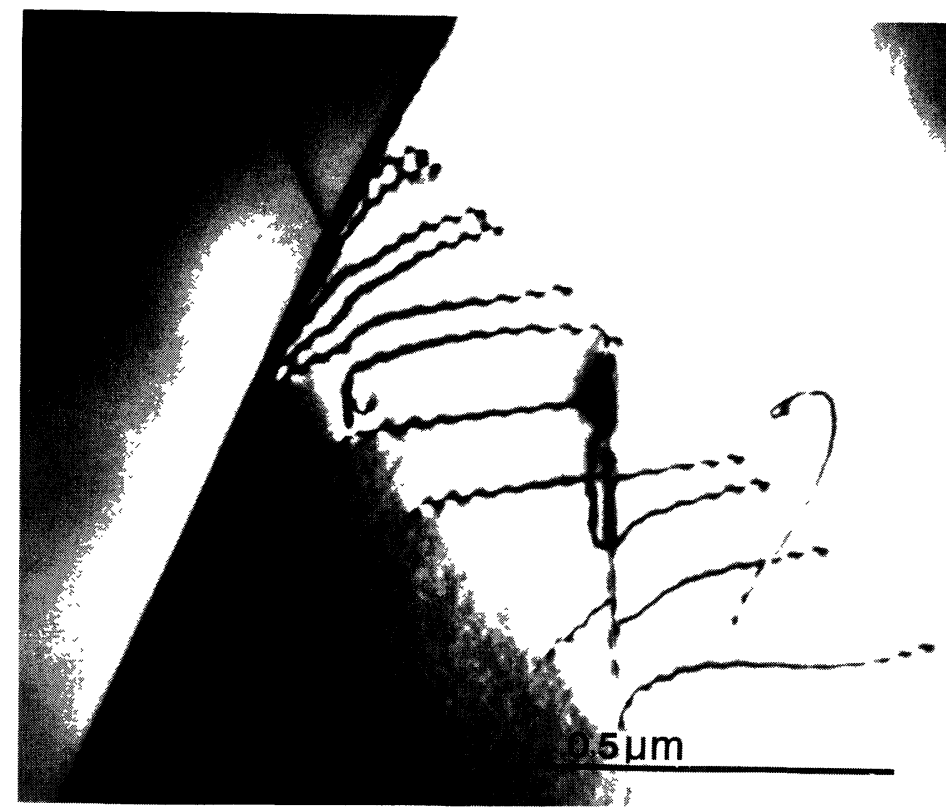

b)

Fig. 4. - $\mathrm{Ni}_{2} \mathrm{CoCr}$. a) In situ deformation. A planar group of 12 dislocations, created in the thin foil, is observed stopped without any apparent obstacle. In front of the group one pair of dislocations is visible. b) In situ deformation. A planar group of 10 dislocations is stopped near a grain boundary, three pairs of dislocations are observed.

Nevertheless it must be noted that the SFE is low, only when Co is added, while the heterogeneous deformation observed still exists in binary $\mathrm{Ni}$-Cr with a high S.F.E. So, this decrease is not sufficient to explain the observed behaviour and the influence of possible ordering must be considered. 
Table II. - Stacking fault energy for various nickel alloys, $T=25^{\circ} \mathrm{C}$.

\begin{tabular}{|c|c|c|c|}
\hline $\mathrm{Ni}$ & $\mathrm{Ni} 26 \% \mathrm{Cr}$ & $\mathrm{Ni} 26 \% \mathrm{Cr} 10 \mathrm{Co}$ & $\gamma$ Phase \\
\hline $140 \mathrm{~mJ} / \mathrm{m}^{2}$ & $76 \mathrm{~mJ} / \mathrm{m}^{2}$ & $28 \mathrm{~mJ} / \mathrm{m}^{2}$ & $21 \mathrm{~mJ} / \mathrm{m}^{2}$ \\
\hline Clément et al. & Clément et al. & Köster et al. & Benyoucef et al. \\
\hline$[12]$ & {$[12]$} & {$[11]$} & {$[8]$} \\
\hline
\end{tabular}

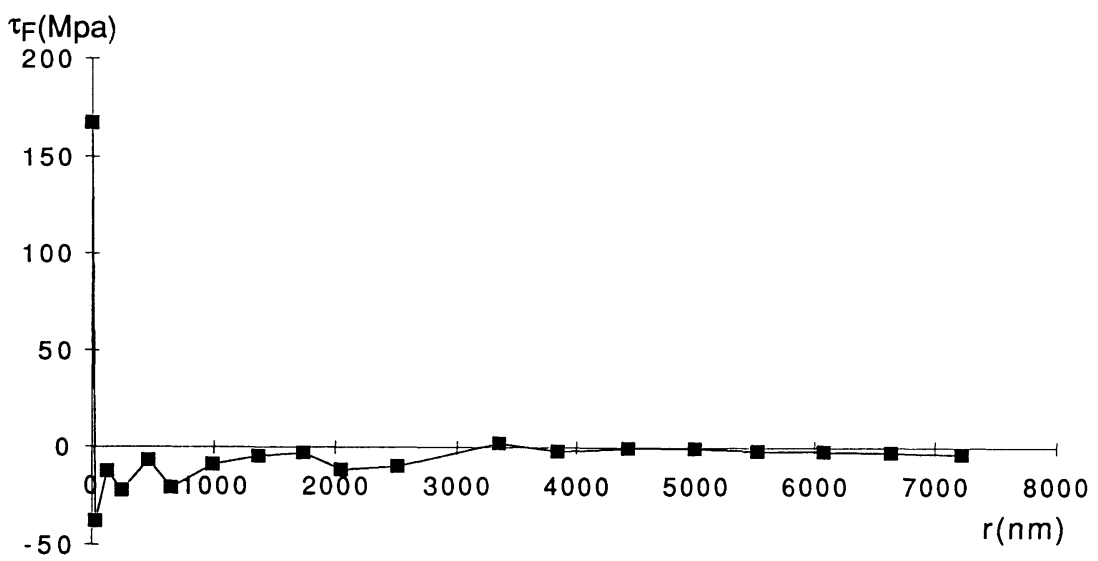

Fig. 5. - Variation along the glide plane of the interaction elastic stress as computed from the measured experimental position of the dislocations of the group observed Figure 2. The friction stress $\sigma_{\mathrm{f}}$, at the head of the pile up is $172 \mathrm{MPa}$. Here $\sigma_{\mathrm{f}} \cong 1.4 \sigma_{\text {el }}$, the elastic limit.

4.2 Friction Stresses. - As high friction stresses seemed to be involved in these materials, it is important to evaluate them. Considering experimental pile-ups, the corresponding friction stresses $\sigma_{\mathrm{f}}$ were estimated with the same method previously used in $\mathrm{Ni}-\mathrm{Cr}$ alloys [4]. As an average they were found (Fig. 5) to be larger than the elastic limit $1.4 \sigma_{\mathrm{el}}<\sigma_{\mathrm{f}}<2.3 \sigma_{\mathrm{el}}$. This is in agreement with the observed behaviour. A single dislocation cannot move under the applied stress alone and pile-ups are thus necessary to concentrate the stress and allow the deformation to proceed. The planar glide observed in the groups is in this case, associated with a softening mechanism. If the first dislocations destroy the ordered arrangement existing in the glide plane, the following ones face a lower resistance to their movement and then remain in the same glide plane.

4.3 Local ORder. - From such observations, the coexistence at room temperature of both short range order and long range order can be proposed:

- a short range ordering because no superstructure spots exist in the diagrams, no precipitates are observed in "weak-beam" observations, a rather constant dissociation width exists between the two Shockley partials for dislocations which are part of pairs [8];

- nevertheless in $\gamma \mathrm{MC2}$, the presence of several pairs of dislocations at the front of the pileups and the increase of both the elastic limit and the number of pairs as the temperature is raised, suggests the existence of a microprecipitation of organized particles. This is confirmed by the existence of $\{100\}$ and $\{110\}$ superstructure spots in the electronic diagram which appear near $750{ }^{\circ} \mathrm{C}$ and image small particles when selected in dark field conditions [28]. 
It is clear also that in the prepared samples the chosen composition corresponds to the equilibrium composition at $850{ }^{\circ} \mathrm{C}$, thus during air cooling a supersaturation in $\gamma^{\prime}$ forming elements might cause the precipitation of some tiny $\gamma^{\prime}$ particles to occur in the $\gamma$ phase. In this hypothesis the reason for pairing is different, if during the deformation a dislocation cuts through a long range ordered particle, its order is destroyed. Dislocations therefore move in pairs, the leading one creates an antiphase boundary and the trailing restores order. The complete shearing of a microprecipitate, whose radius is $r$, is obtained after the crossing of $r / b$ dislocations, ( $b$ is the Bürgers vector of the moving dislocations). Measuring the pair number (from 2 to 6 ) allows the magnitude of the ordered zone to be determined (here $d$ varies from 0.5 to $3.0 \mathrm{~nm}$ ). This value is in good agreement with the dimensions of ordered zones as exhibited by atom-probe techniques which were found to be around 4 to $5 \times 2 d_{002}=1.5$ to $2 \mathrm{~nm}$ (cf. Sect. 6). As they are so tiny this explains why at room temperature, they do not give any superstructure spots in the electron diagrams.

The preceding results can be summarized as follows:

1) at $25^{\circ} \mathrm{C}$ in both $\mathrm{Ni}_{2} \mathrm{CoCr}$ and $\gamma \mathrm{MC} 2$, the deformation proceeds through the creation and propagation of planar groups of mobile dislocations (from 10 to 100);

2) the corresponding friction stress involved was evaluated in $\gamma \mathrm{MC2}$ : it is higher than the elastic limit: $\left(1.4 \sigma_{\mathrm{el}}<\sigma_{\mathrm{f}}<2.3 \sigma_{\mathrm{el}}\right)$;

3) this friction force is correlated to a local order (S.R.O. and/or L.R.O.). In the case of the industrial alloy, $\gamma \mathrm{MC2}$, the existence of a long range order due to $\gamma^{\prime}$ particles is assumed;

4) from the number of paired dislocations in front of the moving groups, the average size of the locally ordered domains was evaluated, it lies between 1.5 to $3.0 \mathrm{~nm}$ for $\gamma \mathrm{MC} 2$.

$\mathrm{X}$-ray measurements and atom probe analysis were conducted in the same samples in order to precise the state of order existing in these different materials.

\section{Study of Chemical Order by Means of Anomalous Scattering Techniques}

In substitutional solid solutions the Warren-Cowley SRO parameters describe the deviations from a random chemical distribution. They can be measured quantitatively by diffuse scattering experiments. From these data, effective atomic interaction energies can be calculated, thus providing a basic knowledge for calculations of thermodynamic properties and phase diagrams. A number of structural data on SRO are available for a variety of binary alloys. On the other hand, there are very few investigations on ternary alloys, due to severe limitations to such measurements: three atomic correlation functions are required to describe the SRO state, instead of one in binary alloys, and special experimental techniques have to be used. The problem may be solved taking advantage of anomalous scattering from atomic elements in the alloy. The SRO state in a $\mathrm{Ni}_{2} \mathrm{CoCr}$ single crystal was studied using this method, with the synchrotron radiation of LUREDCI. $\gamma$-MC2 single crystals were also examined and the SRO state was qualitatively characterized.

5.1 SRO IN $\mathrm{Ni}_{2} \mathrm{CoCr}$. - Diffuse scattering measurements were made using five wavelengths around the $\mathrm{X}$-ray absorption edges of $\mathrm{Cr}$ and $\mathrm{Co}$. The diffuse intensity was measured over 160 points through a volume in reciprocal space bounded by (111), (100), (110), 1/2 (111) positions: at each point of the volume we have five intensity data, measured with different wavelengths. The measurements were made at $100 \mathrm{~K}$ in order to minimize dynamic displacement effects due to thermal vibration of the atoms.

The measurements at the Cr edge show diffuse maxima at the $\{11 / 20\}$ positions. At the Co edge the SRO diffuse scattering is very weak: as a matter of fact, the contribution of the $\mathrm{CoCr}$ and $\mathrm{CoNi}$ atomic pairs is so low that the diffuse intensity distribution is the same at the $\mathrm{Cr}$ edge as at 
the Co edge. This diffuse scattering map undoubtedly indicates the presence of SRO in the alloy. The location of the intensity maxima at the $\{11 / 20\}$ positions suggests a type of SRO similar to that found in binary $\mathrm{Ni}-\mathrm{Cr}$ alloys near the $\mathrm{Ni}_{3} \mathrm{Cr}$ composition $[14,15]$.

Long range order in $\mathrm{Ni}_{3} \mathrm{Cr}$ was never seen, probably because its order-disorder transition temperature is too low and the ordering kinetics too sluggish. However, from SRO measurements, effective pair wise interactions were calculated and a $\mathrm{DO}_{22}$ ordered $\mathrm{Ni}_{3} \mathrm{Cr}$ compound was predicted to be stable, with a transition temperature lower than $150{ }^{\circ} \mathrm{C}$ [14]. For a $\mathrm{DO}_{22}$ structure maxima at both $\left\{\begin{array}{lll}1 & 1 / 2 & 0\end{array}\right\}$ and $\left\{\begin{array}{lll}1 & 0 & 0\end{array}\right\}$ positions are expected. In $\mathrm{Ni}_{2} \mathrm{CoCr}$, there is no diffuse intensity maxima at the $\{100\}$ positions, which indicates that the short range ordered state cannot be pictured as $\mathrm{DO}_{22}$ ordered microdomains or $\mathrm{DO}_{22}$ particles in a disordered matrix.

In a ternary alloy, the diffuse intensity is related to the sum of the Fourier transforms of the three sets of Warren-Cowley SRO parameters relative to the three kinds of pairs: $\mathrm{NiCr}, \mathrm{NiCo}$ and $\mathrm{CoCr}$. These parameters are usually determined by a least squares fitting to the scattering intensity; effective pair interaction potentials are then calculated from these parameters by a method of thermodynamical analysis. Here such a method cannot be used: the contributions of the NiCo and $\mathrm{CoCr}$ pairs are so weak that they remain inside the uncertainty domain of the measurements and the least squares fit gives, for these atomic pairs, unphysical results. A solution was found using a new method [16] based on a formalism developed by Sanchez [17]. This method was called "the $k$-CVM" (Cluster Variation Method in the reciprocal space). It yields effective pair interaction potentials directly from the diffuse scattering via thermodynamical calculations. Thermodynamically coherent SRO parameters are then obtained, by Fourier transform of analytical expressions of the diffuse scattering. This technique was used for two CVM approximations: the point and the pair. The two approximations lead to plausible SRO parameters for the three kinds of pairs.

Tables III and IV respectively give the SRO parameters $\alpha(\mathbf{r})$ and the pair interaction potentials $V_{\mathrm{i}}$ obtained with the pair approximation, for the three kinds of pairs and for the first four shells of

Table III. - SRO parameters for the three kinds of atomic pairs. Values obtained in a $\mathrm{Ni}_{3} \mathrm{Cr}$ single crystal at $560{ }^{\circ} \mathrm{C}$ by Caudron et al. [14] are also given.

\begin{tabular}{|c|c|c|c|c|}
\hline$\alpha(\mathbf{r})$ & $\mathrm{CoCr}$ & $\mathrm{NiCo}$ & $\mathrm{NiCr}$ & $\mathrm{Ni}_{3} \mathrm{Cr}\left(560^{\circ} \mathrm{C}\right)$ \\
\hline 0 & 0.99 & 1.00 & 0.99 & 1.00 \\
\hline 110 & 0.03 & 0.064 & -0.16 & -0.091 \\
\hline 200 & -0.052 & -0.017 & 0.11 & 0.070 \\
\hline 211 & -0.015 & -0.027 & 0.073 & 0.033 \\
\hline 220 & -0.032 & 0.0006 & -0.017 & -0.036 \\
\hline
\end{tabular}

Table IV. - Pair interaction potentials for the three kinds of atomic pairs. Values obtained for $\mathrm{Ni}_{3} \mathrm{Cr}$ by Caudron et al. [14] are reported for a comparison.

\begin{tabular}{|c|c|c|c|c|}
\hline$V($ en meV) & $\mathrm{CoCr}$ & $\mathrm{NiCo}$ & $\mathrm{NiCr}$ & $\mathrm{Ni}_{3} \mathrm{Cr}[14]$ \\
\hline$V_{1}$ & 5.03 & -4.64 & 14.46 & 10.3 \\
\hline$V_{2}$ & 0.24 & 2.06 & -5.38 & -6.2 \\
\hline$V_{3}$ & 0.011 & 1.9 & -4.31 & -1.5 \\
\hline$V_{4}$ & 1.56 & -0.40 & 0.22 & 4.3 \\
\hline
\end{tabular}


020

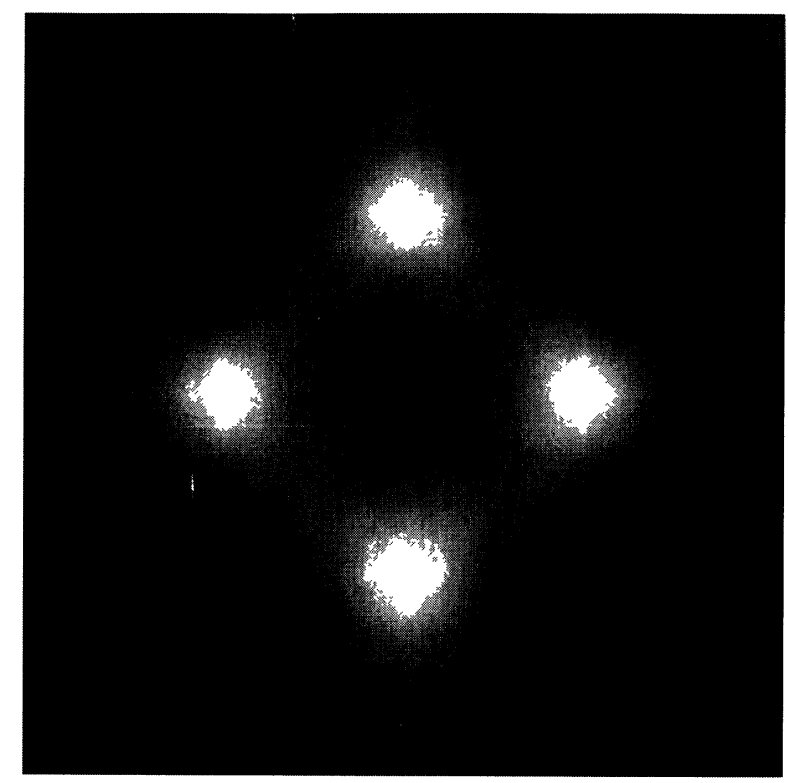

000

002

Fig. 6. - Reconstructed diffuse intensity at the $\mathrm{Cr}$ absorption edge $\left(K_{\mathrm{Cr}}-10 \mathrm{eV}\right)$ in the (100) plane (pair CVM approximation). The intensity scale goes from 23.6 to 64.4 electron units.

nearest neighbours. The reconstructed diffuse scattering in the $\{100\}$ plane is mapped in Figure 6 . The contributions to the diffuse scattering of the minority pairs are presented in Figures 7 and 8 . The results show that the intensity maxima at the $\{11 / 20\}$ positions are due to short range ordering between $\mathrm{Ni}$ and $\mathrm{Cr}$ atoms whereas the $\mathrm{Ni}-\mathrm{Co}$ and the $\mathrm{Co}-\mathrm{Cr}$ pairs give broad intensity humps around the $\{1 / 21 / 20\}$ positions.

Thus order in $\mathrm{Ni}_{2} \mathrm{CoCr}$ quenched from $500{ }^{\circ} \mathrm{C}$ is essentially short range order of special point $\{11 / 20\}$ due to interatomic correlations between $\mathrm{Ni}$ and $\mathrm{Cr}$. The amount of this local order and the interaction energies determined are close to those measured on the $\mathrm{Ni}_{3} \mathrm{Cr}$ alloy [14] that we have reported in Tables III and IV for a comparison: the substitution of Ni by Co does not change much the Ni-Cr interactions. Co does not develop preferential order with $\mathrm{Cr}$. The Co-Ni interactions reveal a tendency towards a Co clustering.

For the Ni-Cr pair, the sign sequence of the $\alpha$ 's recalls that of the $\mathrm{DO}_{22}$ structure, but the amplitude of the oscillation is rapidly damped: the $\alpha$ value for the 8th neighbours ( 400 shells) is 0.03 against 1 in $\mathrm{DO}_{22}$. Beyond this distance (twice the lattice parameter) the $\alpha$ values are near zero (their value for a random distribution). Thus, like in Ni-Cr binary alloys, the correlation length does not exceed a few lattice constants. The observation, by electron microscopy, of three pairs of dislocations at the head of a pile up (Fig. 4) is in agreement with this estimation. In short-range ordered alloys, there is a tendency of dislocations to be in pairs: the presence of long range order is not necessary for pairing to occur. This was explained by Cohen and Fine [18] who have calculated the change in short range order during slip: the $\alpha$ 's do not fall smoothly, large oscillations occur. Due, to these oscillations, energy is released at certain stages of the deformation: the second dislocation moves more quickly than the first and dislocations appear in coplanar groups or pairs, the number of pairs depending upon the correlation length of the SRO: in $\mathrm{Ni}_{2} \mathrm{CoCr}$ as an average 
020

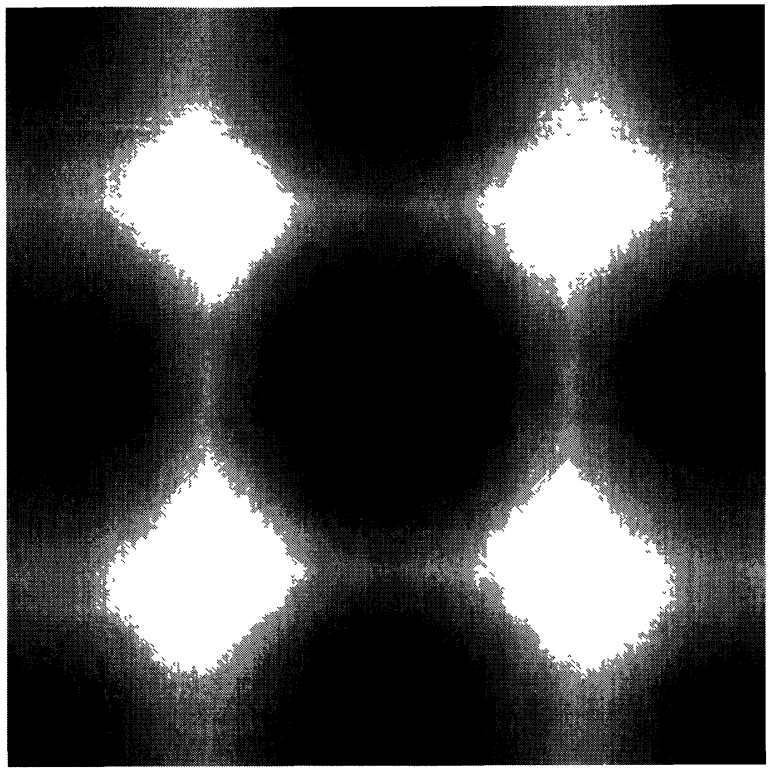

000

002

Fig. 7. - Contribution of the $\mathrm{CoCr}$ atomic pair to the diffuse scattering at the $\mathrm{Cr}$ absorption edge $\left(K_{\mathrm{Cr}}-\right.$ $10 \mathrm{eV}$ ) in the (100) plane (pair CVM approximation). The intensity scale goes from -0.5 to 6.0 electron units.

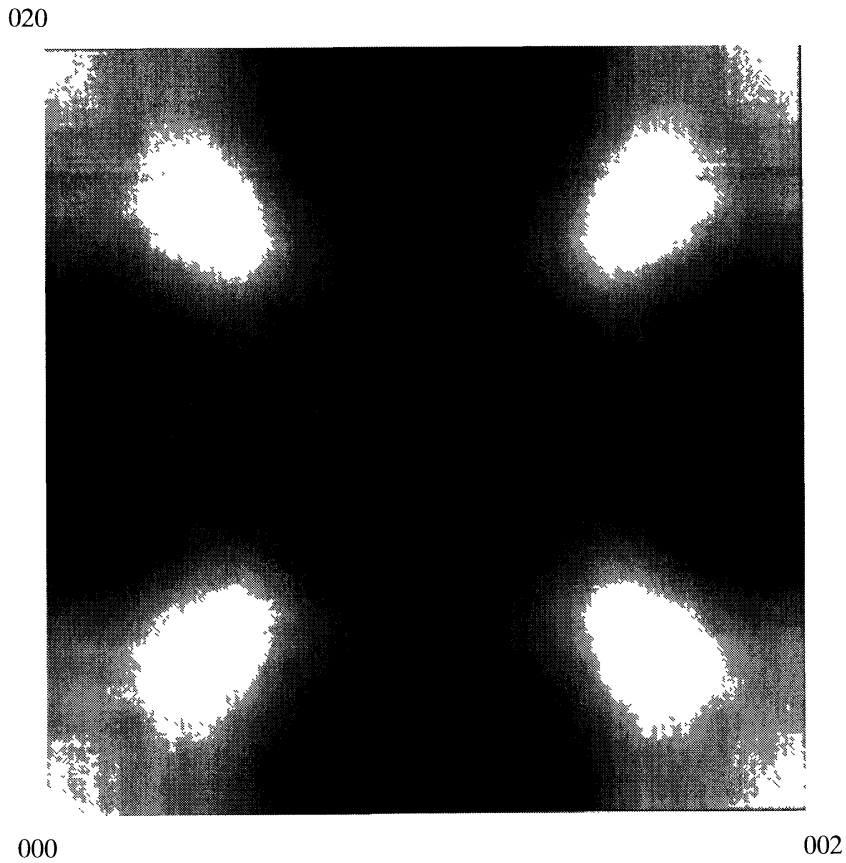

Fig. 8. - Contribution of the NiCo atomic pair to the diffuse scattering at the Co absorption edge ( $K_{\mathrm{Co}}-$ $10 \mathrm{eV}$ ) in the (100) plane (pair CVM approximation). The intensity scale goes from 1.1 to 6.9 electron units. 
the passage of four dislocations globally destroys the SRO in the slip plane, this corresponds to a correlation length of about $1 \mathrm{~nm}$.

5.2 SRO IN $\gamma$-MC2. - Diffuse scattering experiments were made on $\gamma$-MC2 samples after the following heat- treatments:

- $3 \mathrm{~h}$ at $1300^{\circ} \mathrm{C}$ and air quenched,

- $3 \mathrm{~h}$ at $1300^{\circ} \mathrm{C}+1 \mathrm{~h}$ at $600^{\circ} \mathrm{C}$,

- $3 \mathrm{~h}$ at $1300^{\circ} \mathrm{C}+24 \mathrm{~h}$ at $850^{\circ} \mathrm{C}$ and water quenched.

On the first two samples diffuse maxima clearly appear at the $\{11 / 20\}$ positions and only at these positions: this suggests a type of $\mathrm{SRO}$ similar to that found in $\mathrm{Ni}_{2} \mathrm{CoCr}$ and $\mathrm{Ni}_{3} \mathrm{Cr}$. Diffuse scattering measurements were made using two wavelengths near the $\mathrm{X}$-ray absorption edges of $\mathrm{Ni}$ and Cr. Quantitative results are not possible due to the strong mosaic spread of the single crystals (minimum value: $2^{\circ}$ on an area of $5 \mathrm{~mm}^{2}$ ). However, it is clear that the intensity due to SRO does not increase at the $\mathrm{Cr}$ edge. Hence it may be inferred that the contrast is not controlled by the $\mathrm{Ni}-\mathrm{Cr}$ atomic pairs but rather by the presence of $\mathrm{Ni}-\mathrm{Mo}$ and $\mathrm{Ni}-\mathrm{W}$ pairs: $\mathrm{Ni}-\mathrm{Mo}$ and $\mathrm{Ni}-\mathrm{W}$ binary alloys have the same type of SRO, of special point $\{11 / 20\}$.

No diffuse scattering due to local order was detected in the sample quenched from $850{ }^{\circ} \mathrm{C}$ : as expected, SRO decreases with increasing temperature.

$5.3 \gamma^{\prime}$ Micro-Precipitates in $\gamma$-MC2. - From the in situ deformation studies of the $\gamma$ single crystals it was inferred that the chosen composition does not correspond to a single phase domain at low temperature: the solubility of the $\gamma^{\prime}$-like elements decreases with temperature and small $\mathrm{L}_{2}$ precipitates appear.

Surprisingly, we have not detected any trace of $\mathrm{L}_{2}$ phase by $\mathrm{X}$-ray diffraction: we have emphasized that there is no intensity at the $\left\{\begin{array}{lll}1 & 0 & 0\end{array}\right\}$ positions for the two annealing treatments we have studied. Several explanations may be found:

- the amount of $\gamma^{\prime}$ is very small and/or the contrast of the superstructure peaks is not sufficient due to the presence of $\mathrm{Ti}$ and heavy elements on the $\mathrm{Al}$ superlattice;

- the single crystals are not strictly homogeneous;

- the heat treatment was not adequate for the samples studied.

In order to obtain more information about the kinetics of precipitation a study was made by electrical resistivity [19] on a sample quenched from $1000{ }^{\circ} \mathrm{C}$ and annealed at $600{ }^{\circ} \mathrm{C}$. The results are displayed in Figure 9: they show a decrease of the resistivity, beginning after about $30 \mathrm{~h}$ of annealing, which can be attributed to a precipitation. The results for a sample without $\gamma^{\prime}$-like elements ( $\mathrm{Al}, \mathrm{Ti}$ and $\mathrm{Ta})$ are also given for a comparison: in these samples there is no precipitation at $600{ }^{\circ} \mathrm{C}$. Thus, concerning the samples studied by $\mathrm{X}$-ray diffraction, the annealing time at $600{ }^{\circ} \mathrm{C}$ was not sufficient $(1 \mathrm{~h})$ and the equilibrium amount of $\gamma^{\prime}$ at $850^{\circ} \mathrm{C}$ is probably extremely small (sample water-quenched from $850^{\circ} \mathrm{C}$ ): the samples exhibit only SRO.

\section{Atom Probe Investigation of Local Order in $\mathrm{Ni}_{2} \mathrm{CoCr}$ and $\gamma$ Phase}

6.1 ExPerimental. - The Atom Probe (AP) combines the possibilities of the FIM [21] with that of a single particle sensitive time of flight mass spectrometer [22]. A small selected area of the material may be quantitatively analysed with a very high spatial resolution. By field evaporation, the surface atoms of the specimen can be removed and analysed. As a result, a concentration profile may be constructed, layer after layer, with a spatial resolution of one atomic plane in depth. Atom-probe investigation of a material may be interpreted as the analysis of the specimen along 
- $\gamma$-MC2

$\square \gamma$-MC2, where $\mathrm{Al}, \mathrm{Ti}$, Ta have been substituted by $\mathrm{Ni}$

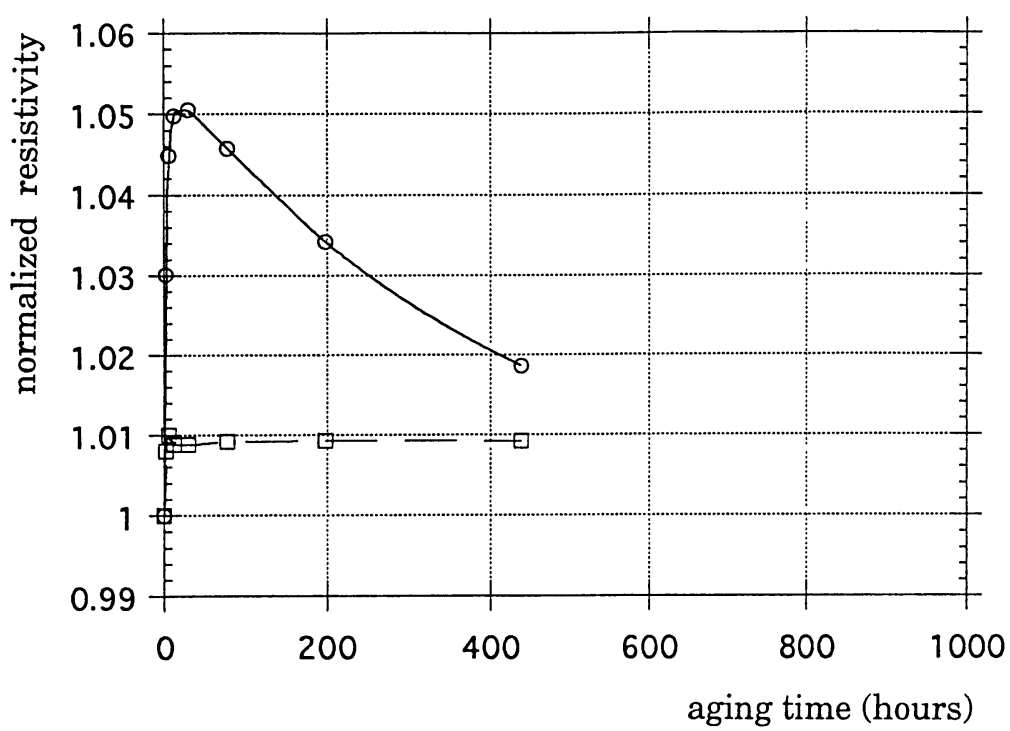

Fig. 9. - Electrical resistivity of $\gamma$-MC2 as a function of aging time at $600{ }^{\circ} \mathrm{C}$. The behaviour of another $\gamma$ alloy, where the $\gamma^{\prime}$-like elements have been eliminated, is also displayed for a comparison.

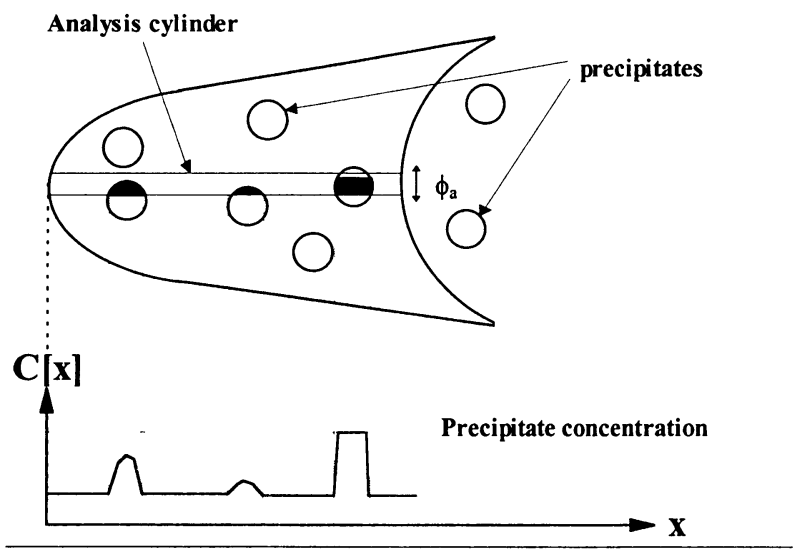

Fig. 10. - Atom-probe microanalysis of material containing finely dispersed particles. The tip radius is typically $50 \mathrm{~nm}$. The diameter of the analysis cylinder $\left(\phi_{\mathrm{a}}\right)$ gives the lateral resolution.

a cylinder (Fig. 10). The lateral resolution is physically limited by the geometrical aberrations in the ion trajectories in the close vicinity of the specimen surface. The highest resolution which can be achieved is typically $0.5 \mathrm{~nm}$ [23]. However, the concept of concentration profile requires the use of a reasonable number of collected ions per layer. In order to maintain the statistical fluctuations to an acceptable level as well as to preserve the lateral resolution, the diameter of the analysed area is usually chosen close to $2 \mathrm{~nm}$. 
The principle of atom-probe techniques is essentially based on two processes [24]: FIM images are obtained by field ionization of a rare gas near the surface of the material and atom-probe microanalysis of the sample is achieved by field evaporation of surface atoms. Both physical phenomena need a very high field $(30-50 \mathrm{~V} / \mathrm{nm})$ which is reached by applying a positive voltage $(\cong 10 \mathrm{kV})$ to the specimen elaborated in the form of a sharply pointed needle $(R \cong 50 \mathrm{~nm})$. The specimen is mounted on a goniometer head and can be rotated in such a way that the specific region of interest (precipitate, grain boundary, a given crystallographic plane) may be mass-analysed. Surface atoms of the specimen are field evaporated by high-voltage pulses $\left(V_{\mathrm{p}}\right)$ which are superimposed to the standing voltage $V_{0}$ (used for FIM images). The mass of chemical species originating from the small selected area is measured by time of flight mass spectrometry: with $n$ the ionization state of the ion, $e$ the charge of electron, $t$ the time of flight and $L$ the flight path.

It is noteworthy to recall that AP techniques do not need the use of ionization ratios. When the experimental conditions are properly settled (a very good vacuum $\left(<10^{-9}\right.$ Torr $)$ is required, the pulse fraction $\left(V_{\mathrm{p}} / V_{0}\right)$ must be high enough $(15-20 \%)$, the tip is held at low temperatures (40 $80 \mathrm{~K})$, low detection rates ( $0.02 \mathrm{ion} /$ pulse) have to be maintained), all field evaporated atoms are ionized and detected with the same efficiency [24]. The compositions are simply deduced from the numbers of collected ions of each nature $(\mathrm{Al}, \mathrm{Ni}, \mathrm{Cr} . .$.$) .$

6.2 Results. - The $\gamma$ phase of nickel base superalloys is often considered as being a random solid solution. However, we already demonstrated that clustering effects could be observed for instance in rhenium-doped superalloys [24]. Chromium concentration modulations were also frequently shown in the $\gamma$ matrix of a number of nickel base alloys [1].

In order to investigate, short range ordering in real space, atom-probe plane by plane analysis were undertaken with a high spatial resolution $(d=2 \mathrm{~nm}$ at the specimen surface).

Tips were elaborated from (001) oriented single crystal $\left(\mathrm{Ni}_{2} \mathrm{CoCr}, \gamma\right.$ phase of $\left.\mathrm{MC} 2\right)$. This direction is the usual solidification axis of single crystal nickel base superalloys [25]. In order to compare results under the same conditions, investigations of both the $\gamma$ phase and $\mathrm{Ni}_{2} \mathrm{CoCr}$ alloys were carried out along this direction.

A typical FIM micrograph of $\mathrm{Ni}_{2} \mathrm{CoCr}$ aged $24 \mathrm{~h}$ at $500^{\circ} \mathrm{C}$ is provided in Figure 11. This image enables a direct observation of surface atoms in real space. The intercept of successive crystallographic planes with the spherical tip apex in various directions gives rise in to this typical contrast of poles (concentric circles). The (001) pole is marked out in this micrograph. By positioning the analysis area of atom-probe in the close vicinity of this pole, it is possible to get a depth profile along (001) direction with a resolution of a single atomic layer. The material is smoothly evaporated. Atomic-planes are thus recorded successively and, in principle, in an individual manner [22].

A typical set of concentration profiles obtained under such conditions is provided in Figure 12. The depth profile related to chromium clearly exhibits the occurrence of short-range modulations with a wavelength equal to the lattice spacing $\left(a=2 d_{002}\right)$. Ni profile undergoes a similar behaviour. However, it is out of phase with respect to Cr. Concentration fluctuations for Co, despite a little bit less clear than those observed for $\mathrm{Cr}$ and $\mathrm{Ni}$, follow the same scheme and appear to be similar to Ni modulations. Cr modulations are shifted of one $d_{002}$ with respect to the two former elements. Note that these concentrations waves were observed to occur over only small distances, a few lattice spacing typically (Fig. 12). Similar short range modulations have been shown to occur in the chromium-rich $\gamma$ solid solution of MC2 superalloy [25]. Concentration histograms displayed in Figure 13 show that composition modulations observed for chromium are not caused by statistical fluctuations. A comparison of experimental frequency distribution with a binomial clearly demonstrates this. In this figure, the frequency to observe a given chromium level in successive layers is plotted against the chromium concentration and is compared to the 


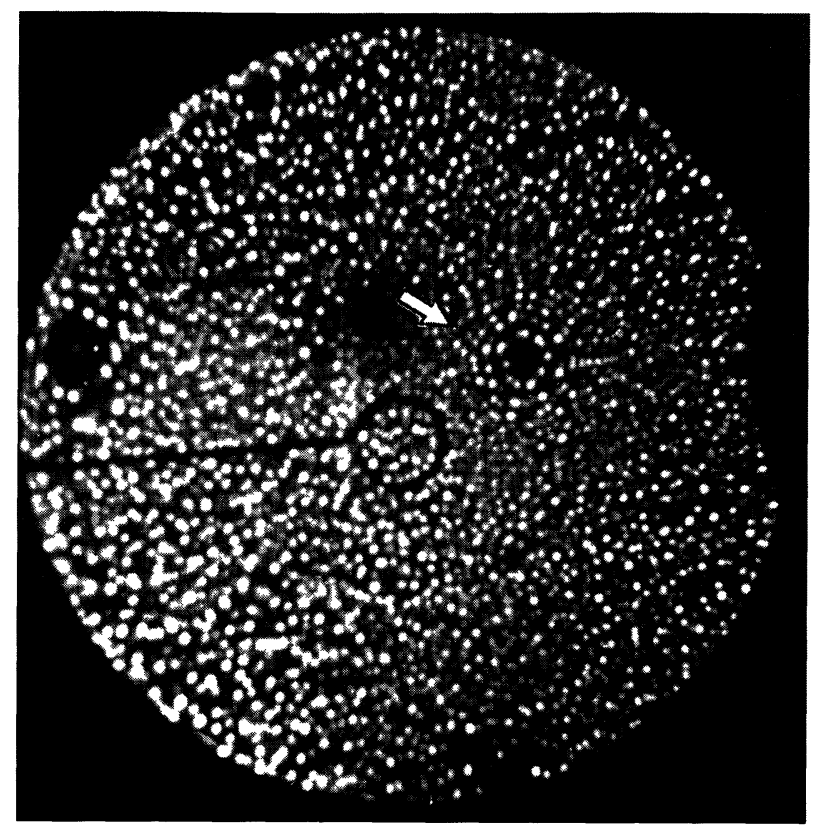

Fig. 11. - FIM micrograph of a (001) oriented single crystal $\mathrm{Ni}_{2} \mathrm{CrCo}$. The magnification is a few $10^{6}$. The central pole arrow is (001).

Table V. - Atom-probe data as compared to concentrations provided by EDX analysis. Unprecisions are given by the standard deviation: $\Delta C=2 \sigma$ with $\sigma=\sqrt{C-1-C) / N}$ and $N$ the number of collected ions.

\begin{tabular}{|c|c|c|c|}
\hline Concentrations (at.\%) & $\mathrm{Cr}$ & $\mathrm{Ni}$ & $\mathrm{Co}$ \\
\hline EDX & 22.75 & 51.25 & 26.00 \\
\hline Atom-probe $N=69031$ at & $23.87 \pm 0.32$ & $50.21 \pm 0.38$ & $25.92 \pm 0.33$ \\
\hline
\end{tabular}

statistical distribution (a binomial). A qui-squared test between both distributions $\left(X_{2}=53\right.$ ) indicates that the hypothesis of a $\mathrm{Ni}-\mathrm{Cr}$ random solution can be rejected with a risk under $5 \%$.

Before to interpret it is important to recall that plane-by-plane analysis can be subjected to specific problems. Preferential retention of a given species from one plane to another may occur [22]. Experimental conditions related to the detection rate, $(<0.01 \mathrm{ion} / \mathrm{pulse})$ the tip temperature $(40 \mathrm{~K})$ as well as the pulse fraction $(20 \%)$ must be carefully checked in order to prevent preferential evaporation or detection pile-up effects to interfere [23]. Table $\mathrm{V}$ gives the proof that, under proper experimental conditions, atom-probe composition data are very close to the expected concentrations as given by EDX analysis. Concentration data as provided by the atom-probe can be considered here as being quantitative.

It is tempting to interpret these local concentrations modulations displayed in Figure 12 in terms of ordered domains. Among the various ordered phase which are predicted to form in the $\mathrm{Ni}-\mathrm{Cr}$ system around 25 at. $\% \mathrm{Cr}$, the $\mathrm{Ni}_{3} \mathrm{Cr}$ phase seems to be a good candidate. This phase has 


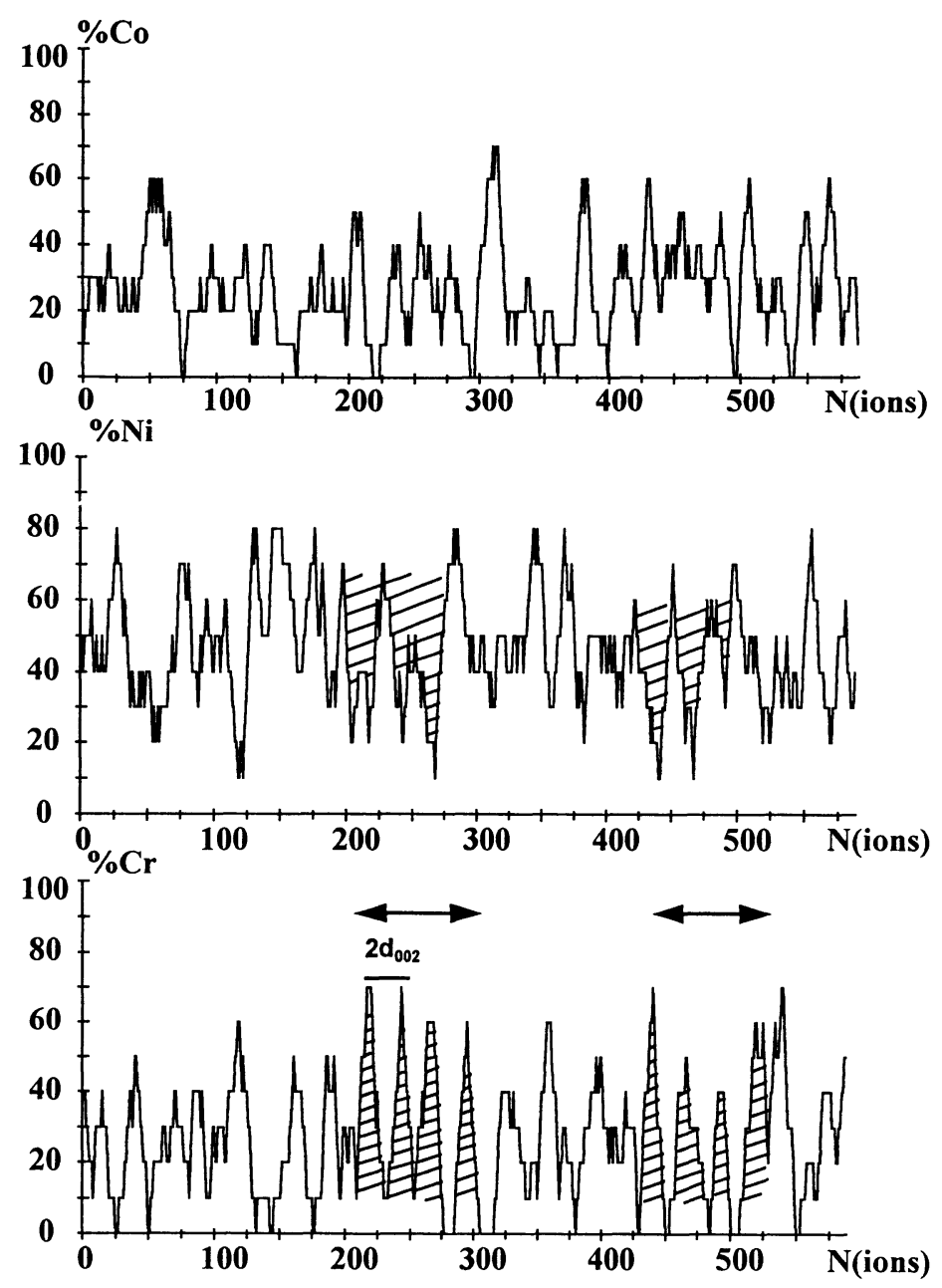

Fig. 12. - Plane by plane analysis of $\mathrm{Ni}_{2} \mathrm{CrCo}$ along the [001] direction. These concentration profiles show that $\mathrm{Cr}$-rich planes alternate with $\mathrm{Ni}+\mathrm{Co}$ enriched planes with a wavelength of $2 d_{002}$. Around 15 ions were detected for each evaporated plane.

a $\mathrm{DO}_{22}$ ordered structure and (001) is one of its superstructure directions. In the framework of this scheme, short range fluctuations observed for $\mathrm{Cr}$ would be related to the crossing of small $\mathrm{Ni}_{3} \mathrm{Cr}$ ordered regions by the "analysis cylinder" (see Fig. 10).

The investigations which were made here by means of Synchrotron anomalous scattering techniques and reported here have shown that short range ordering occurs in $\mathrm{Ni}_{2} \mathrm{CoCr}$ as well as in the $\gamma$ phase. However, the intensity maps exhibit the occurrence of a single special point in $(11 / 20)$ which cannot be interpreted in the scope of small $\mathrm{DO}_{22}$ ordered domains. It should be kept in mind that the $\mathrm{Ni}_{3} \mathrm{Cr}$ ordered structure is expected to form at low temperatures $(\sim 273 \mathrm{~K})$. Even though addition elements could stabilize, the $\mathrm{DO}_{22}$ phase in the complex $\gamma$ phase of industrial superalloys $\mathrm{MC} 2$, it is probably difficult for the material to form ordered domains during cooling after heating $\left(500^{\circ} \mathrm{C}\right)$. In the binary $\mathrm{Ni} \mathrm{Cr}$ system $(19.4$ at \% $\mathrm{Cr})$, Schonfeld et al. showed recently by diffuse neutron scattering that short range ordering also occurs [26]. The authors interpreted 


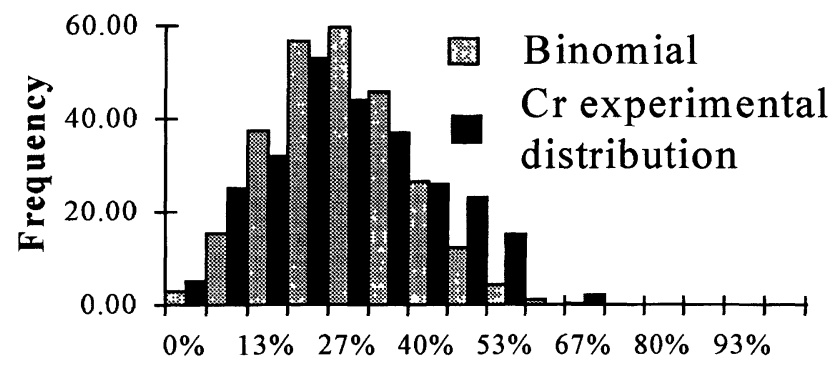

Chromium concentration

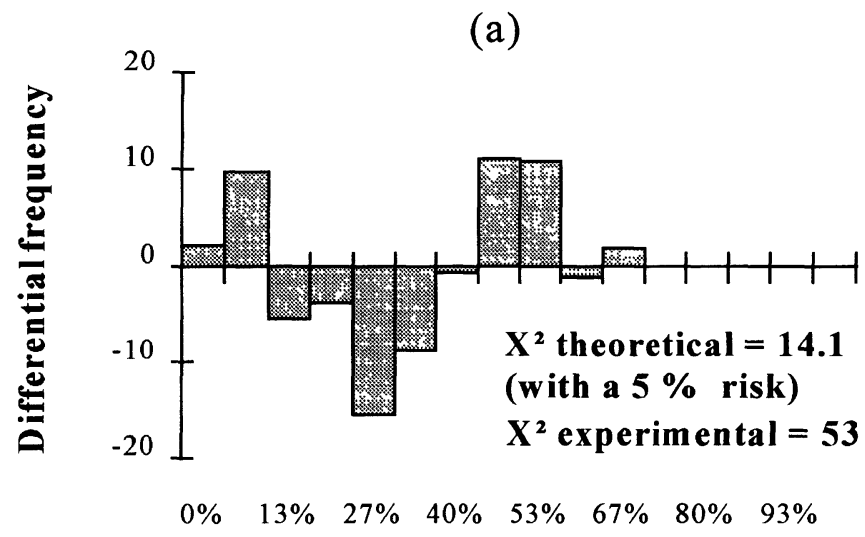

Chromium concentration

(b)

Fig. 13. - (a) Experimental frequency distribution and binomial distribution related to chromium in $\mathrm{Ni}_{2} \mathrm{CrCo}$. The height of each peak is proportional to the number of layers with a given chromium concentration. The binomial is centred on the chromium concentration in the alloy (25 at \%). (b) The differential distribution is the difference between the experimental and the statistical distribution. It clearly exhibits that the distribution of chromium in $\mathrm{Ni}_{2} \mathrm{CrCo}$ is not random: $\mathrm{Cr}$-rich planes and $\mathrm{Ni}+\mathrm{Co}$ enriched planes observed in Figure 12 really occurred and are not caused by statistical fluctuations.

the short range order patterns they obtained on the basis of $(11 / 20)$ concentration waves [26] of imperfectly ordered average clusters, which were earlier described by De Fontaine [27]. The interpretation of (001) concentration waves, which have been observed over one or two nanometers with the atom-probe in real space, in terms of S.R.O as exhibited in reciprocal space by diffuse scattering, is of fundamental interest. However, a full interpretation would require additional investigations and a more detailed analysis of data, which are beyond the aim of this paper.

\section{Conclusion}

From the results of these three investigations using different techniques on the same samples several concluding remarks can be made.

- A strong short range order exists of $\left\{\begin{array}{lll}1 & 1 / 2 & 0\end{array}\right\}$ special point type, in $\mathrm{Ni}_{2} \mathrm{CoCr}$ as well as in 
$\gamma$ - MC2. Between $25^{\circ} \mathrm{C}$ to $600{ }^{\circ} \mathrm{C}$, the corresponding high friction forces $\left(1.4 \sigma_{\mathrm{el}}<\sigma_{\mathrm{f}}<2.3 \sigma_{\mathrm{el}}\right)$, induce in the deformed samples, the collective movement of planar arrays of dislocations.

- In $\mathrm{Ni}_{2} \mathrm{CoCr}$ the correlation length of the SRO at $500{ }^{\circ} \mathrm{C}$ does not exceed a few lattice constants. The presence, in deformed samples, of two pairs of dislocations at the head of planar groups corresponds to a SRO range of $1.0 \mathrm{~nm}$. This SRO is expected to be the cause of the coplanar slip of the dislocations, rather than a low fault energy.

- In $\mathrm{Ni}_{2} \mathrm{CoCr}$ as in $\gamma-\mathrm{MC} 2$, atom-probe plane by plane analyses reveal $\mathrm{Cr}$ and $\mathrm{Ni}$ concentration fluctuations of wavelength near the lattice parameter and of range 1 to $1.5 \mathrm{~nm}$. This observation does not imply that the local atomic structure must be pictured in a microdomain model: X-ray diffraction does not detect $\mathrm{DO}_{22}$ phase. The volume sampled by the atom probe is too small and hence cannot be directly related to an ensemble average. Local frozen-in fluctuations, on a scale of a few lattice constants, are revealed in a system which is macroscopically homogeneous. Monte-Carlo simulations show that the order-disorder transition is lower than $150{ }^{\circ} \mathrm{C}$ [16]. The SRO state measured corresponds therefore to a thermodynamic equilibrium state at high temperature: hence the system is expected to be well described in terms of fluctuating SRO: the time averaged occupation of any lattice site must be the same.

- In the " $\gamma-\mathrm{MC2}$ " samples a fine precipitation of $\gamma^{\prime}$ occurs after annealing at $600{ }^{\circ} \mathrm{C}$ or during air-cooling from $850^{\circ} \mathrm{C}$. Then, the flow stress is known to be strongly influenced. These samples can be fruitfully studied as a model of the $\gamma$ phase in superalloys showing hyperfine precipitates between large $\gamma^{\prime}$ particles. The possible occurrence of this phenomenon in the $\gamma / \gamma^{\prime}$-MC2 superalloy air-cooled from $850^{\circ} \mathrm{C}$ has to be considered.

\section{Acknowledgements}

We gratefully acknowledge P. Caron for elaborating the $\gamma$ matrix MC2 single crystals and A. Bessis for communication of his results prior to publication.

\section{References}

[1] Blavette D., Buchon A. and Chamberland S., Proc. of Euromat, H.E. Exner, V. Shumacher Eds., DGM informationgessellschaft mbh, Oberursel, Germany (1989) pp. 419-424.

[2] Duval S., Chamberland S., Caron P. and Blavette D., Acta. Met. 42 (1994) 185-194.

[3] Clément N., Couret A. and Caillard D., Philos. Mag. A 64 (1991) 670-695.

[4] Clément N., Caillard D. and Martin J.L., Acta Met. 32 (1984) 961.

[5] Hazzledine P.M., Karnthaler H.P. and Wintner E., Philos. Mag. A 32 (1975) 81.

[6] Neühauser H. and Schwink, Material Science and Technology, vol. 6, H. Mughrabi Ed. (VCH, Weinheim, New York, 1993) pp. 191-250.

[7] Gerold V. and Karnthaler H.P., Acta Met. 37 (1989) 2177.

[8] Benyoucef M., Décamps B., Coujou A. and Clément N., Philos. Mag. (1995).

[9] Décamps B., Condat M., Caron P. and Khan T., Scripta Metall. 18 (1984) 1171; Décamps B. and Condat M., J. Microsc. Spectrosc. Electron. 11 (1986) 141.

[10] Benyoucef M., Thèse de l'université de Toulouse (Février 1994).

[11] Köster E.H., Thölen A.R. and Howie A., Philos. Mag. 10 (1964) 1093.

[12] Clément N. and Coulomb P., Philos. Mag. A 30 (1974) 663.

[13] Clément N., Lordre et le désordre dans les matériaux, École d'Hiver, Aussois, France (Les Éditions de Physique, 1984) p. 167. 
[14] Caudron R., Sarfati M., Barrachin M., Finel A., Ducastelle F. and Solal F., J. Phys. I France 2 (1992) 1145.

[15] Shönfeld B., Reinhard L., Kostorz G. and Bührer W., Phys. Status Solidi (B) 148 (1988) 457.

[16] Guillet F., Thèse de l'université Pierre et Marie Curie, Paris (1993).

[17] Sanchez J.M., Physica 111 A (1982) 200.

[18] Cohen J.B. and Fine M.E., J. Phys. Radium 23 (1962) 749.

[19] Bessis A., unpublished results.

[20] Müller E.W.Z., Phys. 131 (1951) 136-142.

[21] Müller E.W.Z., Panitz J.A. and Mc Lane S.B., Rev. Sci. Instrum. 39 (1986) 83-86.

[22] Blavette D., Surf. Sci. 266 (1992) 299-309.

[23] Miller M.K. and Smith G.D.W., Mat. Res. Soc. Pittsburgh PA (1989).

[24] Blavette D., Caron P. and Khan T., Scripta Met. 20 (1986) 1395-1400.

[25] Caron P. and Khan T., Proc. of Euromat (Aachen 1989) H.E. Exmer, V. Schumacher Eds., DGM Informationgessellschaft mbH, Oberursel, Germany (1990) pp. 333-338.

[26] Schonfeld B., Klaiber F., Kostorz G., Zaune U. and Intyre G.Mc., Scripta Metall. 20 (1986) 385-390.

[27] De Fontaine D., Acta Metall. 23 (1975) 553-571.

[28] Glas R., Jouiad M., Caron P., Clément N. and Kirchner H.O.K., to appear in Acta Metall. 